\title{
Boosting Fast and Stable Potassium-ion Storage by Synergistic Interlayer and Pore-structure Engineering
}

Deping Li ${ }^{\text {a, }}$, Qing Sun ${ }^{\text {b }}$, Yamin Zhang ${ }^{\text {b }}$, Xinyue Dai ${ }^{\text {, }}$, Fengjun Ji a, Kaikai Li a , Qunhui Yuan

a , Xingjun Liu ${ }^{\text {a }}$ and Lijie $\mathrm{Ci}^{\text {a, }}$ *

a State Key Laboratory of Advanced Welding and Joining, School of Materials Science and Engineering, Harbin Institute of Technology, Shenzhen, 518055, China

${ }^{\mathrm{b}}$ Research Center for Carbon Nanomaterials, Key Laboratory for Liquid-Solid Structural Evolution \& Processing of Materials (Ministry of Education), School of Materials Science and Engineering, Shandong University, Jinan, 250061, China

*Address correspondence to cilijie@hit.edu.cn; 


\section{ABSTRACT}

Carbon-based material has been regarded as one of the most promising electrode materials for Potassium-ion batteries (PIBs). However, the battery performance based on reported porous carbon electrodes is still unsatisfactory, while the in-depth $\mathrm{K}$-ion storage mechanism remains relatively ambiguous. Herein, we propose a facile "in situ template bubbling" method for synthesizing interlayer tuned hierarchically porous carbon with different metallic ions, which delivers superior K-ion storage performance, especially the rate capability $\left(158.6 \mathrm{mAh} \mathrm{g}^{-1} @ 10.0 \mathrm{~A} \mathrm{~g}^{-1}\right)$ and high-rate cycling stability ( $82.8 \%$ capacity retention after 2000 cycles at $\left.5.0 \mathrm{~A} \mathrm{~g}^{-1}\right)$. The origin of the excellent rate performance is revealed by the deliberately designed consecutive CV measurements, Ex situ Raman tests, GITT and theoretical simulations. Considering the facile preparation strategy, superior electrochemical performance and insightful mechanism investigations, this work can provide fundamental understandings for high performance PIBs and related energy storage devices like sodium-ion batteries, aluminum-ion batteries, electrochemical capacitors and dual-ion batteries.

Key words: Potassium-Ion batteries, Pore-structure engineering, Interlayer engineering, Theoretical Calculations, Ex situ Raman technique. 


\section{Introduction}

Lithium-ion batteries (LIBs) have been widely applied in portable electronic devices owing to their high energy density and long cycling life. ${ }^{1}$ However, the scarce inherence $(\sim 20 \mathrm{ppm})$ and uneven distribution ( $70 \%$ in South America) of lithium resources are hindering their further development in large-scale energy storage systems such as electric vehicles and smart grid. ${ }^{2}$ Therefore, it is of great significance to develop low-cost and high-efficiency energy storage systems based on earth-abundant elements, such as sodium, potassium, calcium, aluminum, magnesium, iron and zinc. ${ }^{3}$ Especially, potassium-ion batteries (PIBs) are attracting tremendous attentions rooting in the high abundance of potassium ( $17000 \mathrm{ppm}, \sim 850$ times higher than lithium) and similar "rocking chair" working mechanism as LIBs. ${ }^{4-6}$ Besides, the redox potential of $\mathrm{K} / \mathrm{K}^{+}$is $-2.93 \mathrm{~V}$ (vs SHE), close to that of $\mathrm{Li} / \mathrm{Li}^{+}(-3.04 \mathrm{~V}$ vs SHE), which will enable a high working potential window and thus ensure a high theoretical energy density of PIBs. ${ }^{7}$ Moreover, the weaker Lewis acidity of $\mathrm{K}$-ion ( $v s$ Li-ion) correlating with a smaller Stoke's radius of solvated ions can facilitate the fast transport kinetics of $\mathrm{K}$ ions in the electrolyte as well as the smoother de-solvation process at the electrode/electrolyte interface. ${ }^{8}$ Furthermore, cost-effective and light-weight aluminum foil rather than expensive copper foil can be applied as the anodic current collector of PIBs, which envisions a better commercial prospect. ${ }^{9}$

Despite the above-mentioned merits, PIBs are facing a tough nut to crack, the large radius of $\mathrm{K}$ ion $(1.38 \AA v s 0.76 \AA$ of Li ion), which makes it difficult to find suitable and endurable electrode materials. As for the cathode side, Prussian blue and its analogues with an open framework structure have been proved stable for reversible $\mathrm{K}$ ion storage. ${ }^{10}$ Nevertheless, as regard to the anode side, $\mathrm{K}$ metal with low melting point $\left(\sim 63^{\circ} \mathrm{C}\right)$ and high reactivity is impractical to be directly applied as a commercial anode considering the potential safety issues. ${ }^{4,11}$ Therefore, the pursuit of stable and durable anode materials for fast and safe potassium ion storage has drawn enormous attentions.

To date, various anode materials, such as carbon-based (graphite/graphitic carbon, ${ }^{12-16}$ hard carbon ${ }^{17-21}$ and soft carbon $\left.{ }^{22,}{ }^{23}\right)$, alloying-type $\left(\mathrm{Sb}^{24} \mathrm{P}^{25} \mathrm{Bi}^{26,}{ }^{27} \mathrm{SnS}_{2}{ }^{28,}{ }^{29}\right.$ and $\left.\mathrm{Sn}_{4} \mathrm{P}_{3}{ }^{30-32}\right)$, conversion-type $\left(\mathrm{FeS}_{2},{ }^{33},{ }^{34} \mathrm{~V}_{3} \mathrm{~S}_{4},{ }^{35} \mathrm{~V}_{5} \mathrm{~S}_{8}{ }^{36}\right.$ and $\left.\mathrm{Co}_{9} \mathrm{~S}_{8}{ }^{37}\right)$ and intercalation-type materials $\left(\mathrm{MoS}_{2},{ }^{38}\right.$ $\mathrm{MoSe}_{2}{ }^{39}$ and $\mathrm{KTiOPO}_{4}{ }^{40,}{ }^{41}$ ) have been widely reported. Among them, carbonaceous materials exhibit a promising prospect owing to their merits like high electronic conductivity, wide availability, environment friendly and low cost. However, as for graphite or graphitic carbons, $\mathrm{K}$ ion can only 
be stored in the interlayer spacing with a relatively low theoretical capacity of $279 \mathrm{mAh} \mathrm{g}^{-1}$ accompanied by a large volume expansion $\left(\sim 61 \%\right.$ by forming $\left.\mathrm{KC}_{8}\right)$, which further results in poor cycling stability and sluggish $\mathrm{K}$ ion diffusion kinetics. ${ }^{6}$

To overcome the above-mentioned obstacles, many efforts have been devoted to optimize the carbon-based anodes. The reported strategies can be mainly classified into the following three categories: i) Interlayer spacing engineering for smoother $\mathrm{K}$ ion insertion and extraction. ${ }^{42}$ For instance, in our previous studies, we successfully intercalate $\mathrm{FeCl}_{3}$ into the interspaces of graphite to expand interlayer distance and thus achieve better cycling stability and rate capability. ${ }^{16}$ ii) Doping heteroatoms $(\mathrm{N}, \mathrm{S}$ and $\mathrm{P})$ or introducing defective sites into the carbon matrix for higher $\mathrm{K}$ ion storage capacity and faster capacitive $\mathrm{K}$ ion storage. ${ }^{43-45}$ Especially, nitrogen doping has been widely investigated and achieved remarkable improvement in the electrochemical performance. Besides, in our recent studies, the inherent correlation between nitrogen dopants and $\mathrm{K}$ ion diffusion kinetics were also preliminarily illuminated. ${ }^{19}$ iii) Pore-structure engineering for fast $\mathrm{K}$ ion diffusion kinetics. The previous studies indicate that highly developed porous structure can facilitate the permeation of electrolyte and transport of $\mathrm{K}$ ions into the interior of the electrode materials, which will facilitate the fast $\mathrm{K}$ ion diffusion and concurrently provide sufficient space for ameliorating the volume expansion. ${ }^{17,} 19,46$ However, there still exists some problems in the above strategies: i) Heteroatom doping sites may trigger side reactions in the initial cycles and bring about low CE (coulombic efficiency), especially ICE (initial coulombic efficiency, merely around 30\%). ii) Most of the reported methods for constructing porous carbons require extra sacrificial agent (e.g. $\mathrm{KOH}$ ), which increases the cost and complexity of the process, further decreasing the practical utility and commercial opportunities. iii) Moreover, the in-depth correlation between the interlayer distance and $\mathrm{K}$ ion diffusion kinetics is still ambiguous, the reported discussions on diffusion behavior and capacitive behavior is still relatively incomprehensive. Therefore, a facile strategy for preparing interspacing-enlarged and pore-tuned carbon, combined with in-depth characterizations and insightful interpretations should be conceived towards better PIBs.

In this work, we propose a facile "in situ self-template bubbling" method, based on which interlayer distance controlled and pore-structure tuned non-graphitic carbon was obtained. The enlarged interlayer distance $(4.17 \AA)$ and abundant meso-/macro-pores can act as the fast $\mathrm{K}$ ion diffusion pathways, which contributes to a superior rate capability $\left(158.6 \mathrm{mAh} \mathrm{g}^{-1} @ 10.0 \mathrm{Ag}^{-1}\right)$ and 
ultra-stable cycling performance ( $\sim 0.0086 \%$ capacity loss per cycle at $5.0 \mathrm{~A} \mathrm{~g}^{-1}$ for 2000 cycles). Besides, the self-etched micropores accompany with a high SSA (specific surface area) can adsorb a large amount of $\mathrm{K}$ ions and deliver a high reversible capacity (360.6 mAh g-1@50 mA g-1). To shed light on the correlation between the interlayer spacing and $\mathrm{K}$ ion diffusion kinetics, the firstprinciple calculations were applied and the intrinsic mechanisms were illuminated. The $\mathrm{K}$ ion diffusion coefficient based on GITT (galvanostatic intermittent titration technique) subsequently verified the DFT results. Consecutive CV measurements were also conducted to decipher the combined $\mathrm{K}$ ion storage behaviors (diffusion-controlled behavior and capacitance-driven behavior) with insightful interpretations of behavior divisions at varied SOCs (state of charges). Furthermore, ex situ Raman measurements were introduced and the highly reversible $\mathrm{K}$ ion storage is confirmed by the reversible change of $I_{D} / I_{G}$ ratios. This work may provide not merely a novel strategy for microstructure-controlled preparation of non-graphitic carbon, but also evaluation model and theoretical guidance towards better carbonaceous electrode materials of PIBs.

\section{a Metal earbonate (template)}

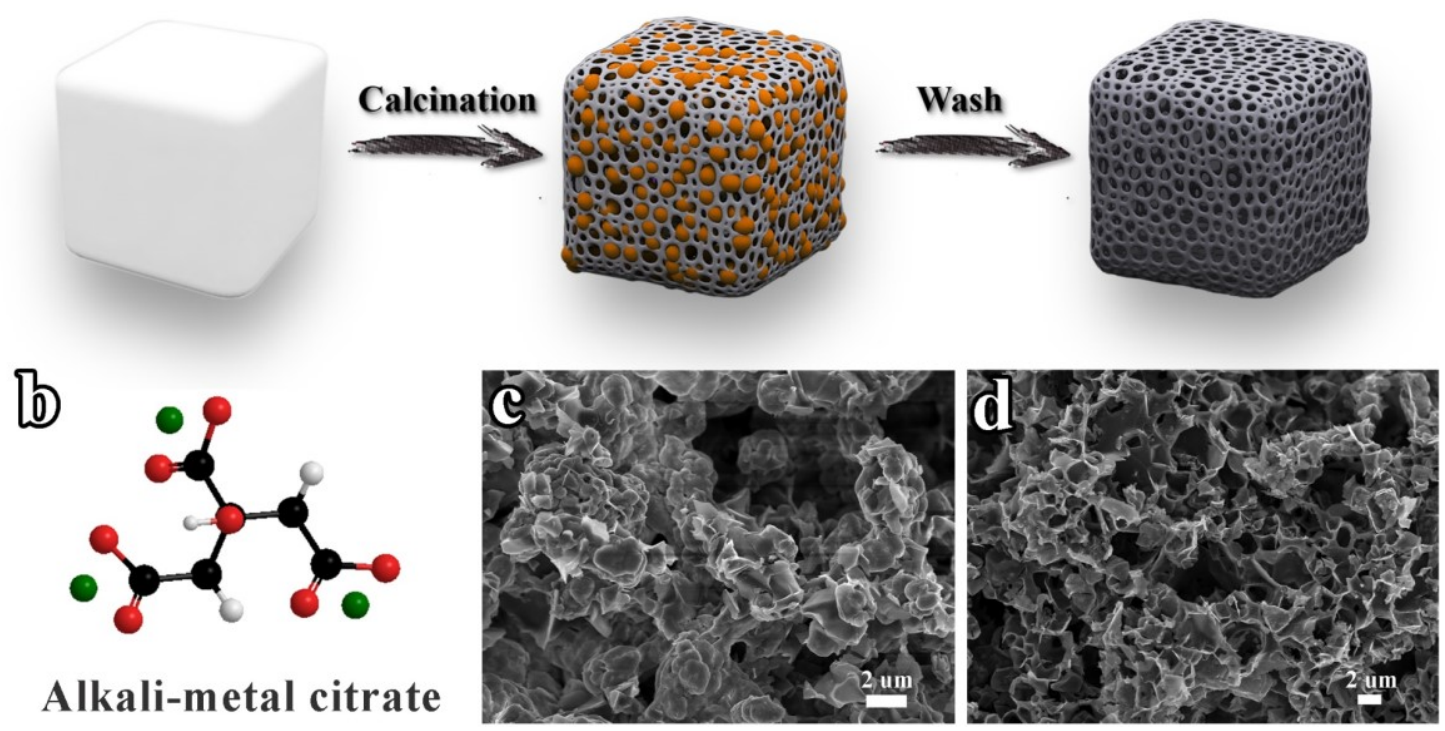

Figure 1. Schematic illustration of the synthetic process of porous carbon based on "in situ selftemplate bubbling" method

\section{Results and Discussion}

\subsection{Morphological and Structural characterization}

Figure 1a illustrates the synthetic process of $\mathrm{LiC}, \mathrm{NaC}$ and $\mathrm{KC}$. After a direct pyrolysis process of metal organic salts (Figure 1b), the precursors can be obtained (LiC-Pre, NaC-Pre and KC-Pre). Along with the decomposition of the organic anions, metal carbonate $\left(\mathrm{M}_{2} \mathrm{CO}_{3}, \mathrm{M}=\mathrm{Li} / \mathrm{Na} / \mathrm{K}\right)$ and 
$\mathrm{CO}_{2}$ can be in situ generated. Metal carbonate can act as the hard template for creating meso- and macro-pores, while $\mathrm{CO}_{2}$ gas can play a role in etching the carbon matrix to create micro-pores $\left(\mathrm{CO}_{2}\right.$ $+\mathrm{C} \rightarrow 2 \mathrm{CO}$ ). After a facile water-washing process, the template can be removed and hierarchically porous carbons can be obtained.

To track the morphological evolution of the carbonaceous materials, SEM characterization was introduced. As shown in Figure 1c and Figure S1a-c, the precursors exhibit a pore-blocking structure. After the removal of template, carbonaceous products with abundant and ringent nanopores can be obtained (Figure 1d and Figure S1d-i). HRTEM images further confirm the wideopen porous structure (Figure S2a, $\mathbf{e}$ and $\mathbf{i}$ ) and indicate the thin-carbon-wall characteristic (Figure S2b, $\mathbf{f}$ and $\mathbf{j}$ ), which is beneficial for the permeation of electrolyte and diffusion of $\mathrm{K}$ ions. XRD measurements were further performed to illuminate the structural evolution process. As plotted in Figure S3, the existence of $\mathrm{Li}_{2} \mathrm{CO}_{3}, \mathrm{Na}_{2} \mathrm{CO}_{3}$ and $\mathrm{K}_{2} \mathrm{CO}_{3}$ is confirmed in the precursors, corresponding to the above-mentioned pore-blocking substances (Figure S1). Particularly, $\mathrm{K}_{2} \mathrm{CO}_{3} \cdot 1.5 \mathrm{H}_{2} \mathrm{O}$ is detected in the XRD pattern of $\mathrm{KC}$-Pre, which should be ascribed to the moisture sensitive feature of $\mathrm{K}_{2} \mathrm{CO}_{3}$. All the XRD patterns of $\mathrm{LiC}, \mathrm{NaC}$ and $\mathrm{KC}$ exhibit a broad (002) peak and a broad (101) peak located at $21 \sim 25^{\circ}$ and $40 \sim 45^{\circ}$, respectively (Figure 2a). Specifically, the (002) can reflect the interlayer spacing distances based on the following Bragg equation: $2 \boldsymbol{d} \boldsymbol{s i n} \boldsymbol{\theta}=$ $\boldsymbol{n} \boldsymbol{\lambda}$. As depicted in Figure 2a, with the shifting (002) peaks to a lower angle, the interlayer distances of $\mathrm{LiC}, \mathrm{NaC}$ and $\mathrm{KC}$ can be calculated to be $3.56 \AA, 3.79 \AA$ and $4.17 \AA$, respectively, which is higher than commercial graphite $(3.35 \AA)$ and is beneficial for the fast $\mathrm{K}$-ion diffusion. ${ }^{47}$ The broad XRD peaks also indicate low graphitization degrees, which is further confirmed by the selected area electron diffraction (SAED) patterns with blurry rings (Figure $\mathbf{2 b}$ and Figure S2d, h, l). To gain a more intuitive view of the expanded interlayer distances, we performed the HRTEM measurements. All samples exhibit short-range-order features, which further supports the above-proved low graphitization degree characteristic (Figure 2c and Figure S2c, g, k) and contributes to faster Kion diffusion kinetics with short diffusion distances. We also calculated the average interlayer distances of the short-range domains ( $3.52 \AA, 3.81 \AA$ and $4.19 \AA$ for $\mathrm{LiC}, \mathrm{NaC}$ and $\mathrm{KC}$, respectively), which is consistent with the XRD results. Raman spectra were also conducted to interpret the structure of the obtained carbonaceous materials. As exhibited in Figure 2d, the spectra show two broad peaks centered at $\sim 1338 \mathrm{~cm}^{-1}$ and $\sim 1588 \mathrm{~cm}^{-1}$, corresponding to the disorder/defect-induced 
$\mathrm{D}$ band an in-plane vibrational $\mathrm{G}$ band, respectively. To get a deeper understanding, we deconvoluted the Raman spectra into five peaks, denoted as $\mathrm{D}_{1}$ band, $\mathrm{D}_{2}$ band, $\mathrm{D}_{3}$ band, $\mathrm{D}_{4}$ band and $\mathrm{G}$ band. ${ }^{48-50}$ The $\mathrm{I}_{\mathrm{D}} / \mathrm{I}_{\mathrm{G}}$ ratio, representing the disorder degree of the graphitic structure or quantities of the structural defects, can be obtained by integrating the area of D band and $G$ band. Specifically, compared with $\mathrm{LiC}$ and $\mathrm{NaC}, \mathrm{KC}$ shows a higher $\mathrm{I}_{\mathrm{D}} / \mathrm{I}_{\mathrm{G}}$ ratio, which indicates a relatively amorphous structure and can provide more accessible pathways for K-ion diffusion.
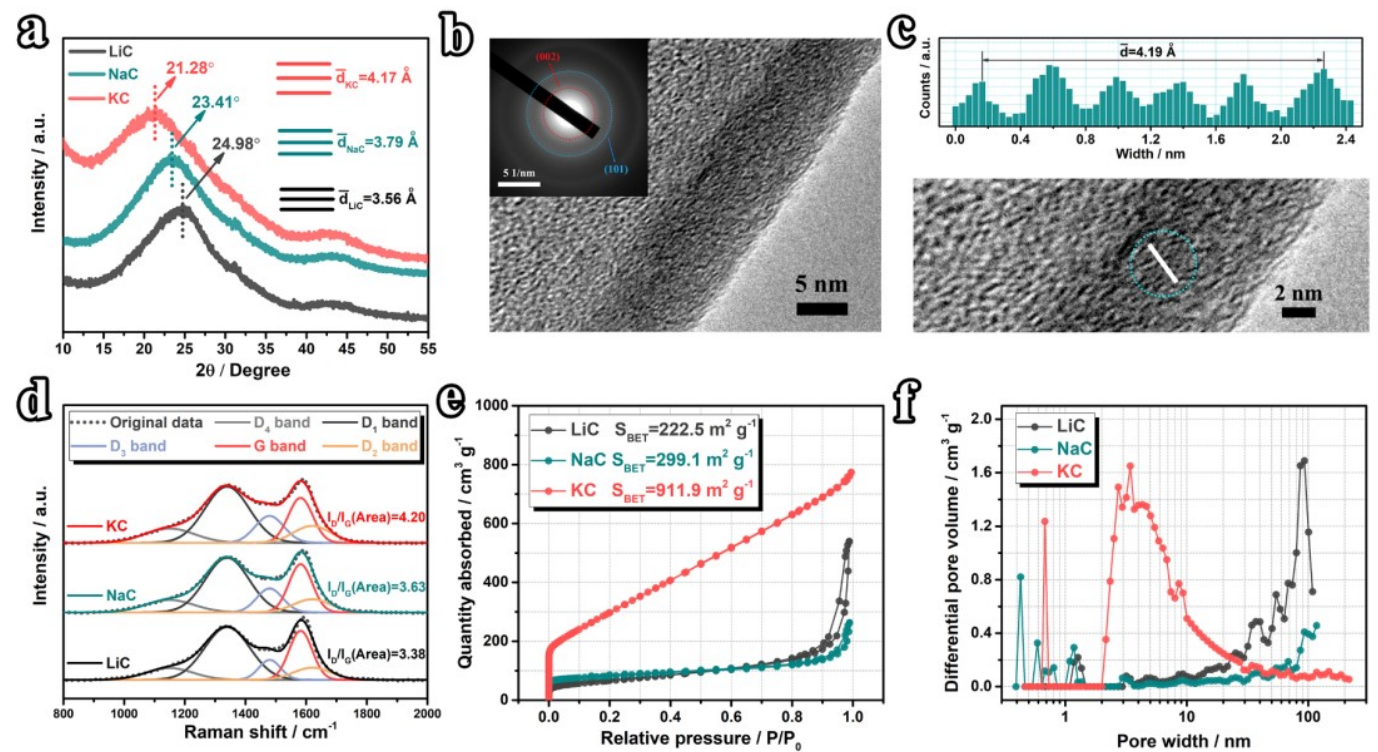

Figure 2. Microstructural characterizations of LiC, $\mathrm{NaC}$ and KC. (a) XRD patterns. (b, c) HRTEM images of KC (inset: SAED pattern, magnified plot is provided in Figure S2). (d) Raman spectra. (e) Nitrogen adsorption-desorption profiles. (f) Pore size distribution results calculated from the adsorption isotherms using DFT method

To grasp a comprehensive understanding of the hierarchically porous structure, $\mathrm{N}_{2}$ adsorptiondesorption method was introduced. As depicted in Figure 2e, the isotherm curves of $\mathrm{LiC}, \mathrm{NaC}$ and KC all exhibit a combination of Type I (typical feature of microporous structure) and Type IV (typical feature of mesoporous materials) characteristics. Concretely, the steep uptake at low $\mathrm{P} / \mathrm{P}_{0}$ region $(<0.05)$ indicates the single layer $\mathrm{N}_{2}$ adsorption and the existence of micropores. The plateau at the medium $\mathrm{P} / \mathrm{P}_{0}$ region $(0.1 \sim 0.9)$ is the characteristic of multilayer $\mathrm{N}_{2}$ adsorption and the existence of mesopores. The uplift at the high $\mathrm{P} / \mathrm{P}_{0}$ region $(0.9 \sim 1.0)$ corresponds to a condensationadsorption behavior and the existence of macropores. ${ }^{19}$ The hierarchically porous structure is further verified by the pore size distribution plot. As depicted in Figure 2f, all samples deliver coexistence of micropore, mesopore and macropore distributions. Specifically, KC exhibits the most abundant mesopores in the range of $2 \mathrm{~nm} \sim 20 \mathrm{~nm}$, which provides efficient and broad channels for $\mathrm{K}$ ion diffusion inside the electrode materials. Besides, $\mathrm{KC}$ shows an intensive distribution of 
ultramicropore $(<1.0 \mathrm{~nm})$ centered at $\sim 0.68 \mathrm{~nm}$, which will boost the capacitive $\mathrm{K}$ ion storage and is subsequently verified in the electrochemical evaluation section (Figure 5 and Figure S6). ${ }^{51}$ Moreover, KC exhibits the highest Brunauer-Emmett-Teller (BET) specific surface area (SSA, $\left.911.9 \mathrm{~m}^{2} \mathrm{~g}^{-1}\right)$ compared with $\mathrm{LiC}\left(222.5 \mathrm{~m}^{2} \mathrm{~g}^{-1}\right)$ and $\mathrm{NaC}\left(299.1 \mathrm{~m}^{2} \mathrm{~g}^{-1}\right)$, which can provide more $\mathrm{K}$ ion adsorption sites and enable a higher specific capacity.

\subsection{Electrochemical Performance}

Inspired by the unique structure of the obtained electrode materials like enlarged interlayer distance and hierarchically distributed pores, the storage capability of large-size $\mathrm{K}$ ion is evaluated. As plotted in Figure 3a and Figure S4a, c, KC electrode exhibits improved cycling stability with a higher reversible capacity $\left(218.3 \mathrm{mAh} \mathrm{g}^{-1}\right)$ and capacity retention ratio $(72.4 \%$ compared with the $11^{\text {th }}$ cycle) after 200 cycles, while $\mathrm{LiC}$ and $\mathrm{NaC}$ electrodes can only maintain reversible capacities of $154.4 \mathrm{mAh} \mathrm{g}^{-1}$ and $196.1 \mathrm{mAh} \mathrm{g}^{-1}$, corresponding to relatively low capacity retention ratios $(57.1 \%$ and 69.2\%). The initial coulombic efficiency (ICE) can be extracted from the galvanostatic charge/discharge (GCD) curves, as displayed in Figure 3b and Figure S4b, d, the ICE of LiC, NaC and $\mathrm{KC}$ electrodes can be calculated as 50.9\%, 48.6\% and 46.0\%, respectively. The slightly decrease in ICE of KC electrode can be attributed to its high SSA which consumes more electrolyte in the initial cycles to form a stable SEI (Solid electrolyte interface) layer. Besides, the GCD curves of KC electrode tend to overlap well after the $20^{\text {th }}$ cycle, which is also in accordance with its higher capacity retention ratio, further illuminating the enhanced cycling stability. Inversely, the capacities of $\mathrm{LiC}$ and $\mathrm{NaC}$ electrodes decrease continuously with the non-overlapping GCD curves. Moreover, the sloping characteristic of GCD curves, combining with the above-mentioned enlarged interlayer distance, high SSA and existence of ultramicropore, conjointly portends kinetic-favorable capacitive behaviors and fast $\mathrm{K}$ ion diffusion rates, thus the rate performance was investigated. As shown in

Figure 3c, $\mathrm{KC}$ electrode delivers a reversible capacity of $360.6 \mathrm{mAh} \mathrm{g}^{-1}$ at $50 \mathrm{~mA} \mathrm{~g}^{-1}$, higher than that of LiC electrode (338.2 $\mathrm{mAh} \mathrm{g}^{-1}$ ) and $\mathrm{NaC}$ electrode (347.7 $\mathrm{mAh} \mathrm{g}^{-1}$ ). Besides, $\mathrm{KC}$ electrode exhibits higher reversible capacities at various current densities from $100 \mathrm{~mA} \mathrm{~g}^{-1}$ to $5000 \mathrm{~mA} \mathrm{~g}^{-1}$. Even at an ultra-high current density of $10000 \mathrm{~mA} \mathrm{~g}^{-1}, \mathrm{KC}$ can still maintain a high reversible capacity of $158.6 \mathrm{mAh} \mathrm{g}^{-1}$, while $\mathrm{LiC}$ and $\mathrm{NaC}$ electrodes can only deliver $48.6 \mathrm{mAh} \mathrm{g}^{-1}$ and 84.7 $\mathrm{mAh} \mathrm{g}^{-1}$, respectively. When the current density was set back to $50 \mathrm{~mA} \mathrm{~g}^{-1}$ after high-rate tolerance test, $\mathrm{KC}$ electrode can still maintain a reversible capacity of $\sim 300 \mathrm{mAh} \mathrm{g}^{-1}$, indicating a good 
reversibility ( $83.2 \%)$, superior to $\mathrm{LiC}\left(213.6 \mathrm{mAh} \mathrm{g}^{-1}, 63.2 \%\right)$ electrode and $\mathrm{NaC}$ electrode $(272.7$ $\left.\mathrm{mAh} \mathrm{g}^{-1}, 78.4 \%\right)$. To get a deeper insight into the superior rate capability of $\mathrm{KC}$ electrode, the capacity retention ratio normalized with the capacity at $50 \mathrm{~mA} \mathrm{~g}^{-1}$ was plotted in Figure 3d. The capacity retention ratio of $\mathrm{KC}$ electrode is obviously higher than $\mathrm{LiC}$ and $\mathrm{NaC}$ electrodes at all current densities. Especially, at a super-high current density of $10000 \mathrm{~mA} \mathrm{~g}^{-1}$, the capacity retention ratio of $\mathrm{KC}$ electrode $(\sim 4 \%)$ is $\sim 3.1$ times and 1.8 times higher than $\mathrm{LiC}$ electrode and $\mathrm{NaC}$ electrode, respectively.
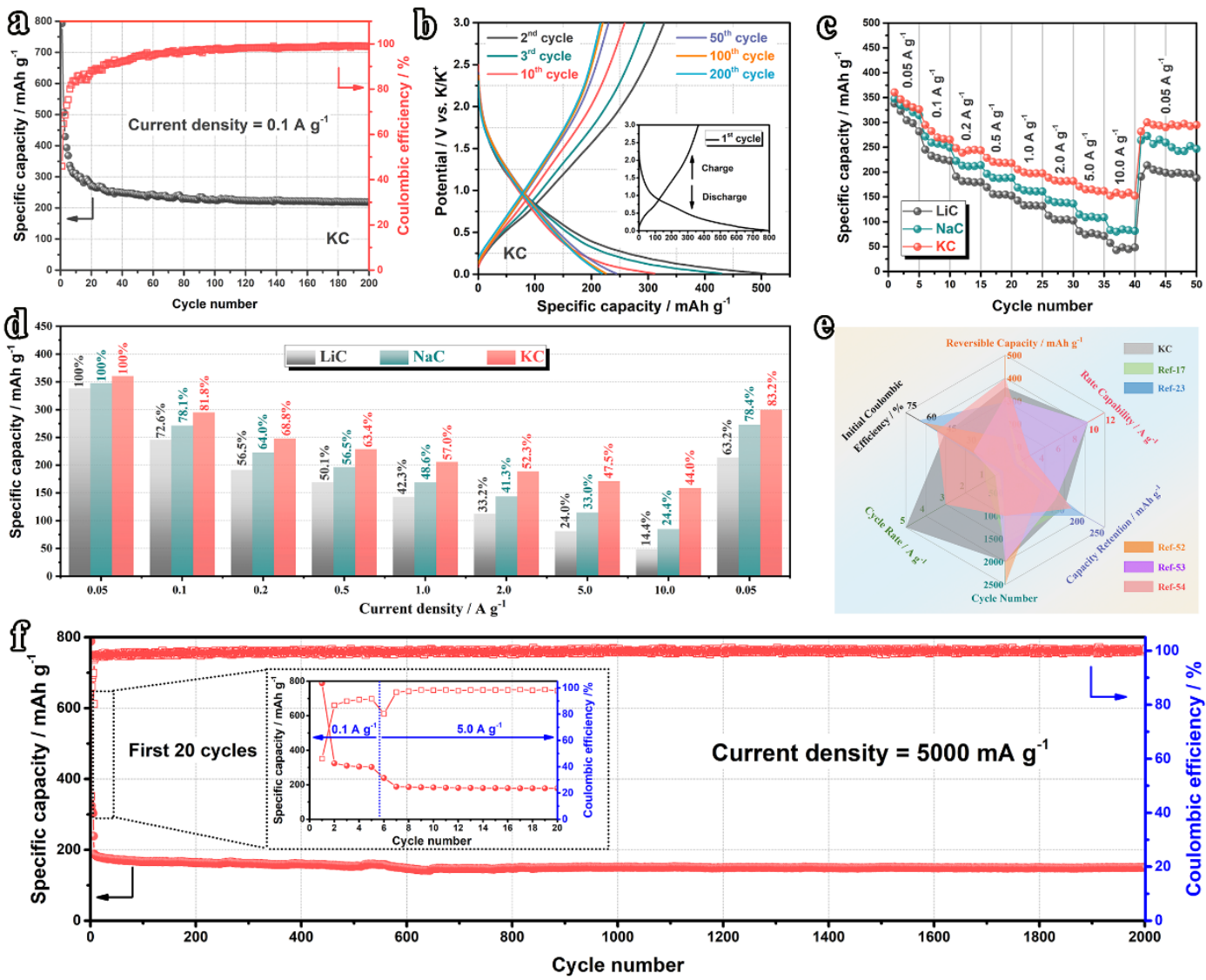

Figure 3. Electrochemical evaluations. (a) Cycling performance and (b) voltage profiles of KC electrode at $0.1 \mathrm{~A} \mathrm{~g}^{-1}$. (c) Rate capability. (d) Capacity retention ratios at various current densities. (e) Electrochemical comparisons with recently reported literatures. (f) Long-term cycling performance at high rate of $5.0 \mathrm{~A} \mathrm{~g}^{-1}$ (inset: the first twenty cycles)

Enlightened by the superior rate capability, we further evaluated the long-term cycling stability at a high current density of $5000 \mathrm{~mA} \mathrm{~g}^{-1}$. The electrode is pre-activated at $100 \mathrm{~mA} \mathrm{~g}^{-1}$ for 5 cycles to form a stable SEI layer on the surface. As depicted in the inset of Figure 3f, the KC electrode shows a gradually increasing coulombic efficiency (CE) in the initial 10 cycles and keeps $\sim 100 \%$ in the subsequent cycles. As expected, the KC electrode exhibits impressive cycling stability with a capacity of $151.2 \mathrm{mAh} \mathrm{g}^{-1}$ after 2000 cycles, corresponding to a high capacity retention ratio of $82.8 \%$ 
(compared with the capacity of $11^{\text {th }}$ cycle). However, $\mathrm{LiC}$ and $\mathrm{NaC}$ electrodes cannot suffer comparable cycles at such high rate (Figure S5). After merely 800 cycles, the capacities of LiC and $\mathrm{NaC}$ electrodes drop sharply to $52.3 \mathrm{mAh} \mathrm{g}^{-1}$ (50.4\%) and $22.1 \mathrm{mAh} \mathrm{g}^{-1}$ (15.0\%), respectively. Besides, the $\mathrm{CEs}$ of $\mathrm{LiC}$ and $\mathrm{NaC}$ electrode fluctuate obviously, especially after the $500^{\text {th }}$ cycle, while the $\mathrm{CE}$ of $\mathrm{KC}$ electrode keeps stable after the $11^{\text {th }}$ cycle and the average $\mathrm{CE}$ is quite close to $100 \%(\sim 99.66 \%)$. To address the superiority of the synergistic interlayer and pore-structure engineering, we compared the electrochemical performance of $\mathrm{KC}$ electrode with recently reported carbonaceous electrode materials. As concluded and depicted in Figure 3e and Table S1, based on the selected crucial electrochemical parameters, $\mathrm{KC}$ electrode overmatches most of the reported carbonaceous materials. ${ }^{17,23,52-54}$ Especially, the rate capability of $\mathrm{KC}$ is at the apex, which indicates a smooth and fast $\mathrm{K}$ ion diffusion process enabled by the synergistic interlayer and pore-structure engineering.

\subsection{Kinetic Simulation and Experimental Verification}

To elucidate the stable and fast $\mathrm{K}$ ion insertion/extraction kinetics of $\mathrm{KC}$ electrode, we designed theoretical simulations on the energy cost for $\mathrm{K}$ ion insertion into carbon as a function of carbon interlayer distance. The calculation is based on the balance of attractive van der Waals interactions between adjacent carbon layers and repulsive interactions between $\mathrm{K}$ ions and carbon, ${ }^{55}$ and the calculated results can reflect the energy consumed for K-ion intercalating into carbon layers to from $\mathrm{KC}_{8}$ compound (Figure 4a). As plotted in Figure 4b, with the increasing interlayer distances, the energy barrier gradually decreases to $0 \mathrm{eV}$, indicating that higher interlayer distances could contribute to faster $\mathrm{K}$ ion diffusion kinetics, which is also in accordance with the better rate capability of $\mathrm{KC}$ electrode compared with $\mathrm{LiC}$ and $\mathrm{NaC}$ electrodes. The minimum energy barrier is theoretically achieved at $5.2 \AA(\sim 0 \mathrm{eV})$, which is also close to the theoretical interspacing of stage1 potassium intercalation compounds $\left(\mathrm{KC}_{8}, 5.35 \AA\right)$, attesting the effectiveness of our constructed calculation models. Moreover, the uplift of the curve at a higher interlayer distance should be ascribed to the weak van der Waals interactions between $\mathrm{K}$ ion and carbon layers, which results in a relatively unstable structure and consumes more energy to keep the balance. 

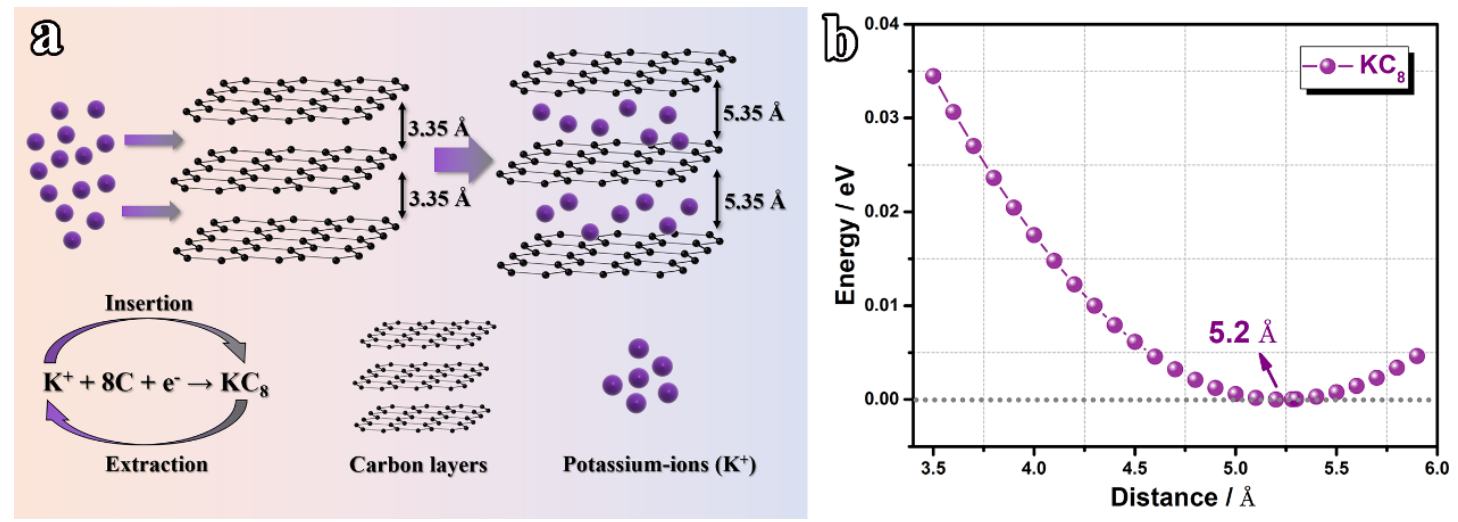

Figure 4. Theoretical studies. (a) Diagrams of $\mathrm{K}$ ions intercalate into carbons and form stable $\mathrm{KC}_{8}$ compounds. (b) Theoretical energy consumed for $\mathrm{K}$ ion stored in carbon as a function of carbon interlayer distance

With the superiority of interlayer engineering theoretically demonstrated, we also designed consecutive cyclic voltammetry (CV) measurements to verify the effectiveness of the pore-structure engineering. As exhibited in Figure 5a and Figure S6a, d, CV curves of all samples exhibit a broad peak at $\sim 0.6 \mathrm{~V}$ in the initial cathodic cycle, which can be attributed to the decomposition of electrolyte and formation of the SEI layer. This peak gradually disappears in the subsequent cycles, indicating that a stable SEI layer can be formed in the initial cycles. The sharp cathodic peak at $\sim 0.1$ $\mathrm{V}$ corresponds to the step intercalation of $\mathrm{K}$ ions into carbon to form $\mathrm{K}$-intercalated compound. Accordingly, the broad peak at $\sim 0.4 \mathrm{~V}$ represents the de-intercalation of $\mathrm{K}$ ions. The $\mathrm{CV}$ curves can also be divided into two parts, one exhibits distinct redox peaks representing K-ion insertion/extraction process (low-potential region, $<0.4 \mathrm{~V} v s . \mathrm{K} / \mathrm{K}^{+}$), the other one shows a quasirectangular shape indicating the existence of $\mathrm{K}$ ion capacitive adsorption/desorption process (highpotential region, $>0.4 \mathrm{~V} v s . \mathrm{K} / \mathrm{K}^{+}$) which is a kinetic-favorable $\mathrm{K}$-ion storage behavior. As plotted in Figure 5b and Figure S6b, e, the de-potassiation peak current increases and expands to cover higher potential range along with the increasing scan rates, suggesting the capacitive characteristic. To grasp a deep understanding of the mixed $\mathrm{K}$ ion storage behaviors (diffusion and capacitive behaviors), we introduced the following Eq. (1) and Eq. (2) proposed by Dunn's group: ${ }^{56-58}$

$$
\begin{gathered}
i=a v^{b} \\
\log (i)=b \log (v)+\log (a)
\end{gathered}
$$

Where $\boldsymbol{a}$ and $\boldsymbol{b}$ are adjustable constants, $\boldsymbol{i}$ the peak current, and $\boldsymbol{v}$ the scan rate. The $\boldsymbol{b}$-value could be determined by plotting $\log (\mathrm{i})-\log (\mathrm{v})$ curves. Particularly, when $\boldsymbol{b}$-value is close to 0.5 , the electrochemical reaction is dominated by the diffusion-controlled process; As the $\boldsymbol{b}$-value 
approaches 1.0, the capacitive process (surface-driven behavior) predominates. In our cases, as plotted in Figure S7, $\boldsymbol{b}$ values at all selected potentials are in the range of 0.5 1.0, indicating the existence of mixed behaviors. As concluded in Figure 5c, KC electrode shows higher $\boldsymbol{b}$ values compared with $\mathrm{LiC}$ and $\mathrm{NaC}$ electrodes, indicating a larger proportion of capacitive behavior and is consistent with its better rate capability. Moreover, higher $\boldsymbol{b}$ values of all electrodes locate in the potential range higher than $0.4 \mathrm{~V}$, which sheds more light on the potassiation process in carbonaceous materials. Specifically, a capacitance-controlled behavior initiates in the high potential region and a following diffusion-controlled process comes up in the low potential region, which is also in accordance with the shape of CV curves plotted in Figure 5a. The mixed behaviors were further quantified based on the following Eq. (3) and Eq. (4): ${ }^{56-58}$

$$
\begin{gathered}
i=k_{1} v^{1 / 2}+k_{2} v \\
i v_{v^{1 / 2}}=k_{1}+k_{2} v^{1 / 2}
\end{gathered}
$$

Where $\boldsymbol{k}_{1}$ and $\boldsymbol{k}_{2}$ are constants, $\boldsymbol{k}_{1} \boldsymbol{v}^{1 / 2}$ represents the contribution of diffusion-controlled reaction and $\boldsymbol{k}_{2} \boldsymbol{v}$ stands for the contribution from capacitive behavior. As concluded in Figure 5d, KC electrode delivers a $36 \%$ capacitive contribution ratio at a low scan rate of $0.1 \mathrm{mV} \mathrm{s}^{-1}$, which gradually increases to $93 \%$ at an ultra-high scan rate of $20.0 \mathrm{mV} \mathrm{s}^{-1}$, illuminating the origin of the superior rate capability. Besides, the capacitive contribution ratios of $\mathrm{LiC}$ and $\mathrm{NaC}$ electrodes are relatively low, which is also in accordance with their lower $\boldsymbol{b}$ values and unsatisfying rate performance. To gain a more intuitional impression, the representative CV profiles are plotted (Figure 5e and Figure S6c, f), demonstrating that the capacitive contribution (the blue section) is dominant in the overall capacity at a relatively high scan rate of $2.0 \mathrm{mV} \mathrm{s}^{-1}$. Besides, the area above $0.4 \mathrm{~V}$ is almost entirely covered by the blue area, while the low potential region demonstrates a dominant diffusioncontrolled behavior, which further verifies the results in Figure 5c. 

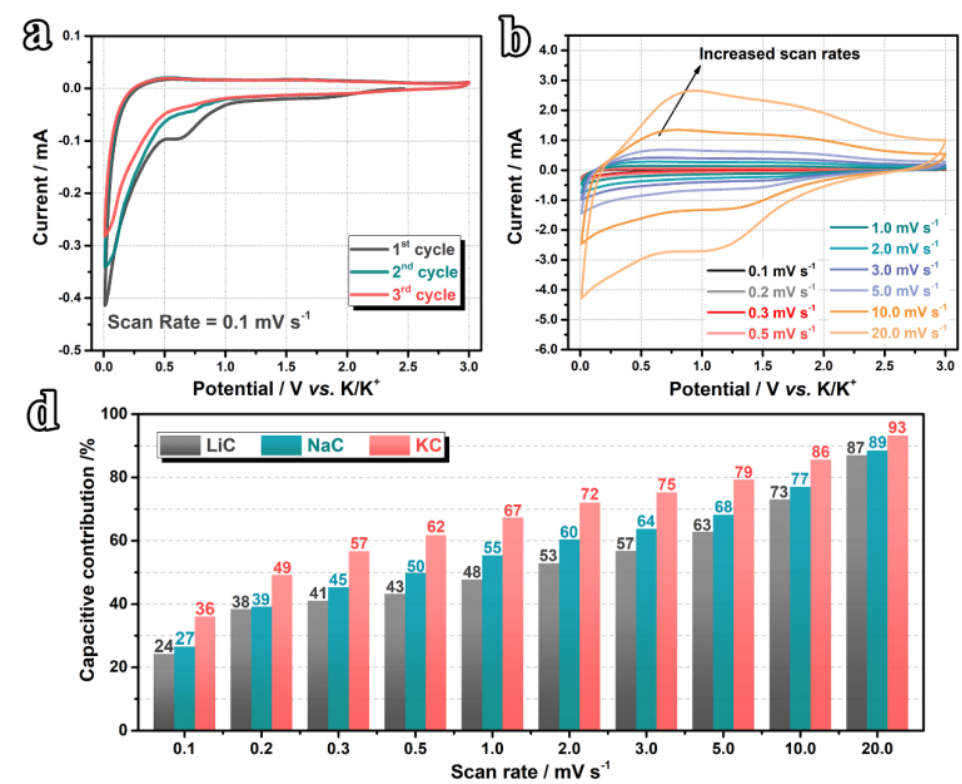
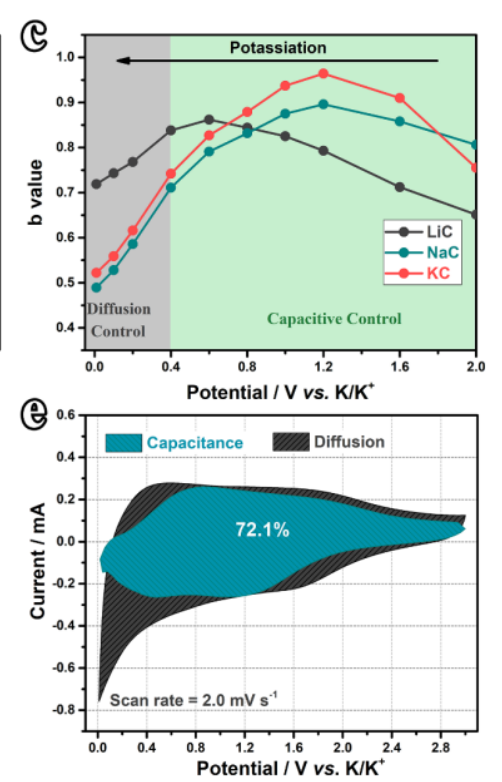

Figure 5. Studies on $\mathrm{K}$ ion storage behaviors. (a) $\mathrm{CV}$ curves at $0.1 \mathrm{mV} \mathrm{s}^{-1}$ and (b) various scan rates of $\mathrm{KC}$ electrode. (c) $\boldsymbol{b}$ values as a function of potential. (d) Capacitive contribution ratios at various scan rates. (e) Sketch view of the capacitive contribution of $\mathrm{KC}$ electrode at $2.0 \mathrm{mV} \mathrm{s}^{-1}$

With the superiority of the synergistic interlayer and pore-structure engineering theoretically verified in the microstructural level, we further conducted GITT (Galvanostatic intermittent titration technique) tests to evaluate the $\mathrm{K}$ ion diffusion kinetics in the cell level. The diffusion coefficient of K ions $\left(D_{k}\right)$ can be calculated based on the following Eq. (5): ${ }^{30,59,60}$

$$
D_{k}=\frac{4}{\pi \Delta t}\left(\frac{m_{B} V_{M}}{M_{B} S}\right)\left(\frac{\Delta E_{S}}{\Delta E_{\tau}}\right)^{2}
$$

Where $\boldsymbol{m}_{\boldsymbol{B}}$ is the mass of the active material in the electrode, $\boldsymbol{M}_{\boldsymbol{B}}$ and $\boldsymbol{V}_{\boldsymbol{M}}$ the molar mass and molar volume of the electrode material, and $\boldsymbol{S}$ the geometric area of the electrode. Here, $\boldsymbol{M}_{\boldsymbol{B}} / \boldsymbol{V}_{\boldsymbol{M}}$ can be obtained from the density of electrode materials. Other parameters in Eq. (5) could be obtained according to Figure S8. The potential change and calculated coefficient are plotted as a function of potassiation/de-potassiation depth (Figure 6a, b and Figure S6). Obviously, KC electrode exhibits higher diffusion coefficient compared with $\mathrm{LiC}$ and $\mathrm{NaC}$ electrodes at various potassiation/depotassiation depths, demonstrating a faster $\mathrm{K}$ ion transportation kinetic rooting from the enlarged interlayer distance and well-developed pore structure. Besides, at a deep potassiation state $(>80 \%)$, slight fluctuation can be observed in the value of $\mathrm{D}_{\mathrm{k}}$, indicating the occurrence of diffusioncontrolled $\mathrm{K}$ ion storage, which is a relatively sluggish process compared with the capacitive behavior, further confirming the above-mentioned results in Figure 5c.

A sketch of the synergistic pore-structure and interlayer engineering is plotted in Figure 6c-d. 
Firstly, the porous structure provides broad and sufficient $\mathrm{K}$ ion diffusion pathways, the permeation of electrolyte in the interior of the electrode is also guaranteed; Secondly, the large SSA and pores distributed below $1.0 \mathrm{~nm}$ can act as active sites for kinetic-favorable capacitive K-ion storage with higher reversible capacity achieved simultaneously; Thirdly, the enlarged interlayer distance and relatively amorphous structure decreases the diffusion distance between carbon layers and reduces the energy barrier of $\mathrm{K}$ ion transportation; Moreover, the intrinsic high electronic conductivity of the carbon skeleton ensures the fast transport of electrons. Overall, all the above features facilitate the enhanced K ion storage capability of KC electrode.
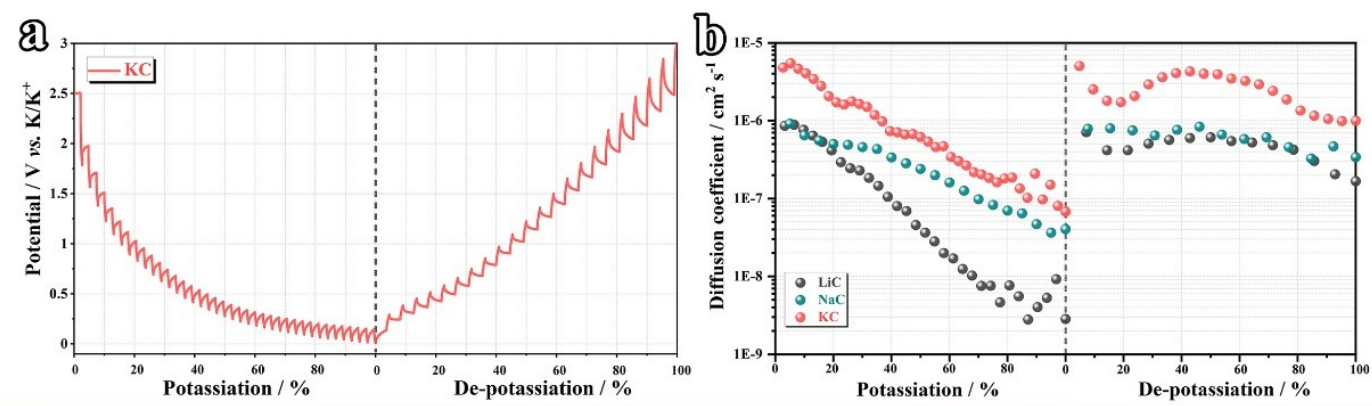

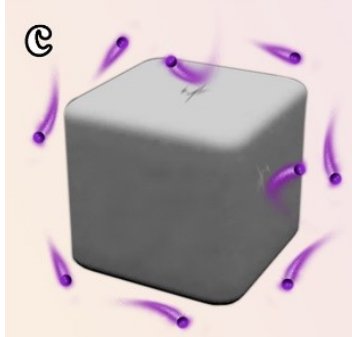

Bulk electrode

Baffled $\mathrm{K}^{+}$transport

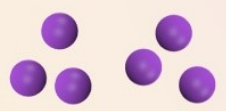

Potassium ion $\left(\mathrm{K}^{+}\right)$

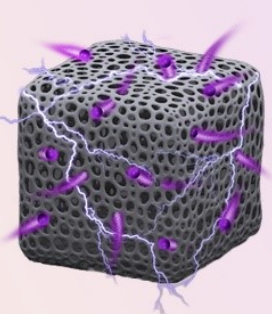

Porous electrode

Boosted $\mathrm{K}^{+} \& \mathrm{e}^{-}$transport

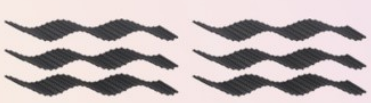

Carbon layers
@]

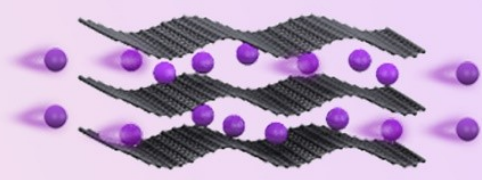

Sluggish $\mathrm{K}^{+}$diffusion in tight inerspacing
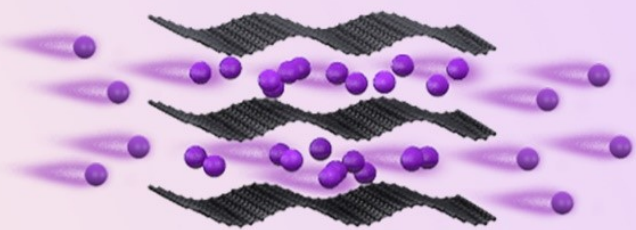

Favorable $\mathrm{K}^{+}$diffusion in broad interapscing

Figure 6. Studies on $\mathrm{K}$ ion diffusion kinetics. (a) GITT profile of $\mathrm{KC}$ electrode. (b) Diffusion coefficients of LiC, $\mathrm{NaC}$ and $\mathrm{KC}$ electrode. Schematic illustrations of the boosted K-ion storage capability enabled by (c) pore-structure engineering and (d) interlayer engineering.

\subsection{Ex situ electrochemical investigations}

To shed more light on the combined K-ion storage behaviors, ex situ Raman spectra were recorded at various SOCs (state of charges, Figure 7b) for insightful mechanism understandings. Similar as the Raman spectra in Figure 2d, the collected spectra were also deconvoluted for accurate interpretations. As plotted in Figure 7a, three obvious phenomena could be observed. Firstly, $\mathrm{D}_{2}$ peak (side peak of G peak, the light orange curve) keeps decreasing from OCP (open circuit potential) 
to $\sim 0.01 \mathrm{~V}$ (full-potassiation state), corresponding to a $\mathrm{D}_{2} / \mathrm{G}$ ratio dropping from 2.24 to 1.66 , which exactly demonstrates the K-ion adsorption behavior at the defective sites. During the potassiation process (recharge to $3.0 \mathrm{~V}$ ), a gradually strengthened $\mathrm{D}_{2}$ peak was observed followed by $\mathrm{D}_{2} / \mathrm{G}$ ratio rising to 2.12 , indicating the highly reversible K-ion storage process. Secondly, the overall $\mathrm{I}_{\mathrm{D}} / \mathrm{I}_{\mathrm{G}}$ ratio by area exhibits the similar trend as $\mathrm{D}_{2} / \mathrm{G}$, which decreases at deeper potassiation states (from 4.08 to 2.45 ) and recovers alongside the K-ion desorption (from 2.45 to 3.76 ), further illuminating the capacitive K-ion storage behavior. Thirdly, a slight red shift of G band from $1585 \mathrm{~cm}^{-1}$ (OCP) to $1578 \mathrm{~cm}^{-1}(\sim 0.01 \mathrm{~V})$ can be observed, originating from the stretching of the in-plane C-C bond induced by K-ion intercalation process. With the battery recharged back to $3.0 \mathrm{~V}, \mathrm{G}$ band shifts back to $1583 \mathrm{~cm}^{-1}$, indicating the reversible $\mathrm{K}$-ion intercalation/extraction process. ${ }^{18,}{ }^{25}, 61$ Briefly speaking, based on the results of ex situ Raman spectra, the combined K-ion storage mechanisms and the reversibility were clearly illuminated.
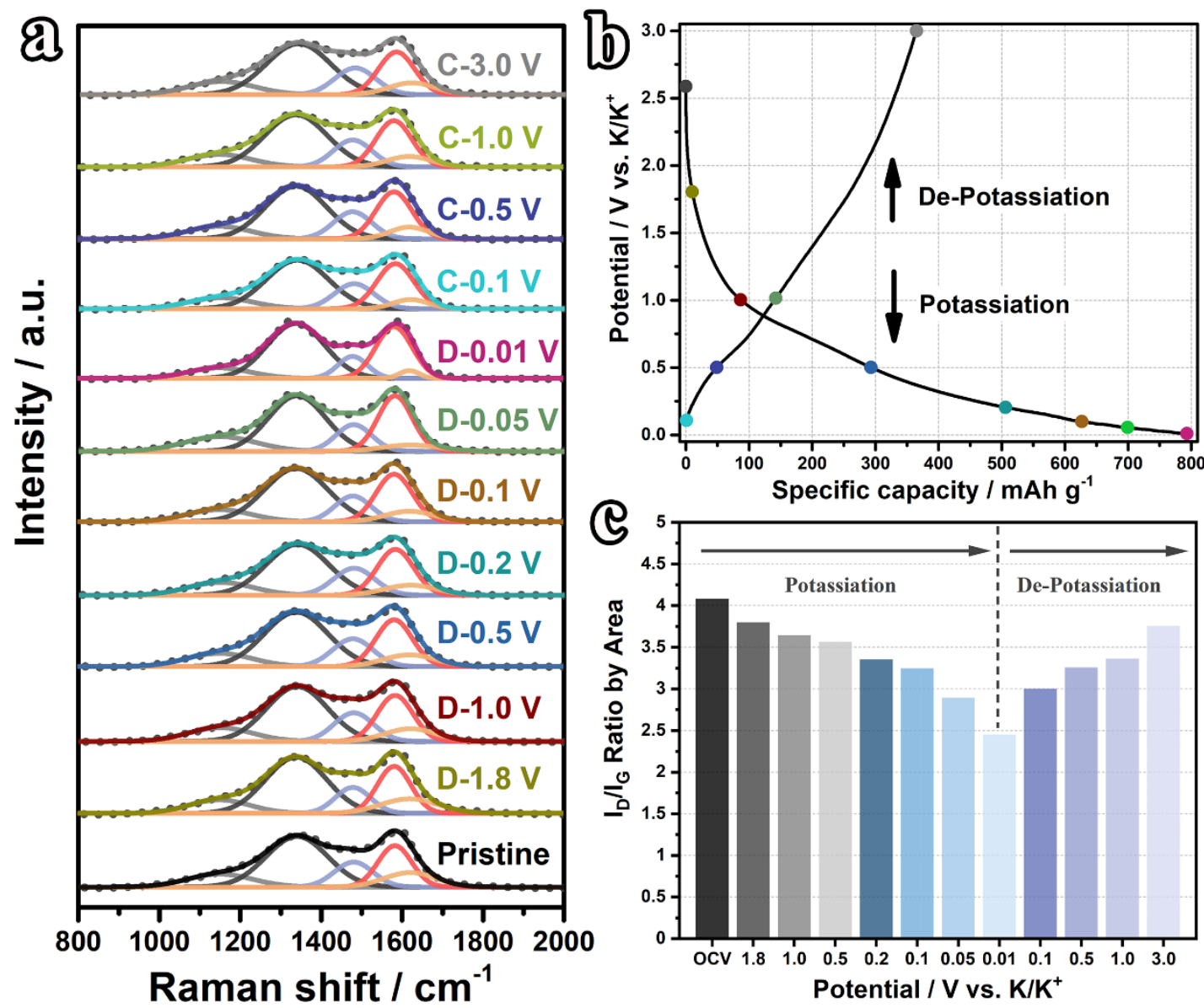

Figure 7. Studies on K-ion storage mechanisms. (a) Ex situ Raman spectra of KC electrode in the first cycle. (b) Potential profile of the first cycle with selected potential points. (c) $I_{D} / I_{G}$ ratios at selected potentials 


\section{Conclusion}

In summary, we propose a facile preparation method using different metallic ions for hierarchically porous carbonaceous electrode materials with tunable interlayer distances. Under deliberately designed interlayer and pore-structure engineering, the as-prepared electrode exhibits superior K-ion storage capability, outperforming most of the reported materials, especially at rate capability. Theoretically, the results of DFT calculations shed light on the correlations between interlayer distance and $\mathrm{K}$-ion diffusion kinetics. In short, a larger interlayer spacing corresponds to a smoother K-ion diffusion process. Experimentally, the results of consecutive CV measurements and ex situ Raman spectra confirm the co-existence of diffusion-controlled and capacitive K-ion storage behaviors. And the predominated capacitive behavior contributes to the enhanced rate capability and high reversible capacity. Overall speaking, the enlarged interlayer distance boosts the $\mathrm{K}$ ion diffusion rate between carbon layers, while the hierarchically porous structure facilitates the capacitive K-ion adsorption at edges, micropores and defective sites, which clarifies the origin of the superior rate capability of KC electrode. Furthermore, GITT measurements verifies the increased $\mathrm{K}$-ion diffusion coefficient of $\mathrm{KC}$ electrode in the cell level, further illuminating the practical prospect. The comprehensive and insightful investigations of this work may provide a fundamental paradigm for constructing high performance carbonaceous electrode materials towards various energy storage systems.

\section{Experimental Section}

4.1 Preparation of LiC, $\mathrm{NaC}$ and $\mathrm{KC}$ : $\mathrm{LiC}$ was prepared by direct carbonization of lithium citrate tribasic tetrahydrate $\left(\mathrm{C}_{6} \mathrm{H}_{5} \mathrm{Li}_{3} \mathrm{O}_{7} \cdot 4 \mathrm{H}_{2} \mathrm{O}\right)$ at $650^{\circ} \mathrm{C}$ for $2 \mathrm{~h}$ under $\mathrm{Ar}$ (Purity $>99.999 \%$ ) atmosphere with a temperature ramp rate of $2^{\circ} \mathrm{C} \min ^{-1}$. Afterwards, the as-obtained dark product was washed with diluted hydrochloric acid $(0.1 \mathrm{M} \mathrm{HCl})$, deionized water and absolute ethyl alcohol in sequence. After being dried in a vacuum oven at $60^{\circ} \mathrm{C}$ for $10 \mathrm{~h}$, the final product was obtained and denoted as LiC. Analogously, $\mathrm{NaC}$ and $\mathrm{KC}$ were prepared under the same protocol except the raw materials are sodium citrate tribasic dehydrate $\left(\mathrm{C}_{6} \mathrm{H}_{5} \mathrm{Na}_{3} \mathrm{O}_{7} \cdot 2 \mathrm{H}_{2} \mathrm{O}\right)$ and potassium citrate tribasic monohydrate $\left(\mathrm{C}_{6} \mathrm{H}_{5} \mathrm{~K}_{3} \mathrm{O}_{7} \cdot \mathrm{H}_{2} \mathrm{O}\right)$.

4.2 Materials Characterization: The morphology and microstructure of the as-synthesized materials were characterized by FESEM (JEOL JSM-7800F) and TEM (JEOL JEM-2100). The 
phase structure was determined by XRD on a Rigaku Miniflex 600 X-ray diffractometer operated at $40 \mathrm{kV}$ with $\mathrm{Cu} \mathrm{K} \alpha$ radiation $(\lambda=1.5406 \AA)$ at a scan rate of $5^{\circ} \min ^{-1}$ (step length $\left.=0.01^{\circ}\right)$. Raman spectra were collected on a Renishaw inVia confocal Raman microscope using a $633 \mathrm{~nm}$ laser as the excitation source. The SSA (Specific Surface Area) and PSDs (Pore Size Distributions) were determined by $\mathrm{N}_{2}$ adsorption isotherm at $-196^{\circ} \mathrm{C}$ on a Micromeritics ASAP 2020 analyzer, the samples were outgassed at $150^{\circ} \mathrm{C}$ for $8 \mathrm{~h}$ before the analyzing procedure.

4.3 Electrochemical Measurements: The working electrode was prepared by mixing $80 \mathrm{wt} . \%$ active materials (as-synthesized LiC, $\mathrm{NaC}$ or $\mathrm{KC}$ ), $10 \mathrm{wt}$ \% super P and $10 \mathrm{wt}$ \% PVDF (polyvinylidene fluoride). PVDF (concentration: 3wt.\%) was pre-dissolved in NMP (N-Methyl pyrrolidone) solvent before being added as binder. The slurry was then coated onto aluminum foil and dried at $90^{\circ} \mathrm{C}$ in a vacuum oven for $10 \mathrm{~h}$ to evaporate the solvent. Circular electrodes with a diameter of $14 \mathrm{~mm}$ were obtained using a punch machine and the average mass loading of each electrode was $1.0 \sim 1.2 \mathrm{mg}$. The coin cells (type: CR-2032) were assembled in an Ar-filled glove box $\left(\mathrm{H}_{2} \mathrm{O}<1.0\right.$ ppm and $\mathrm{O}_{2}<1.0$ ppm) with metallic potassium platelet as the counter electrode. A Whatman GF/C glass fiber was applied as the separator. The electrolyte was $0.8 \mathrm{M} \mathrm{KPF}_{6}$ solution with a mixed solvent of ethylene carbonate and diethyl carbonate (1:1 by volume). The galvanostatic charge/discharge tests were conducted within the voltage window of 0.01-3.0 V using a LAND-CT2001A multichannel galvanostat (Wuhan, China) at room temperature $\left(25^{\circ} \mathrm{C}\right)$. The $\mathrm{CV}$ profiles were obtained within the same voltage range at various scan rates on an electrochemical workstation (Autolab, Metrohm). GITT (Galvanostatic Intermittent Titration Technique) were conducted under repeated current pulse (100 $\left.\mathrm{mA} \mathrm{g}^{-1}, 10 \mathrm{~min}\right)$ and relaxation (40 min). For ex situ Raman measurements, the cycled electrodes were disassembled from the coin cells in an argon-filled glove box and then rinsed in DEC solvent to dissolve the residual electrolyte followed by vacuum-drying at $60^{\circ} \mathrm{C}$ for $10 \mathrm{~h}$ before the characterizations.

4.4 DFT calculations: To calculate the equilibrium between the graphite layers in the presence of $\mathrm{K}$ ion, a modified method was employed according to previously reported work. ${ }^{55}$ Specifically, the balance of attractive van der Waals forces between graphite layers and the interactions between the $\mathrm{K}$ ion and the graphite sheets was firstly determined. As reported, the quantitive value of van der Waals force per unit area between two graphene layers can be calculated according to the following equation: ${ }^{2}$ 


$$
\boldsymbol{f}=-\frac{\mathrm{A}}{\boldsymbol{r}^{4}}, \text { where the constant } \mathrm{A} \approx 0.40 \mathrm{eV} \AA
$$

Besides, the equilibrium distance for $\mathrm{K}$ ion adsorption onto graphite surface is $2.70 \AA$, corresponding to an adsorption energy of $1.12 \mathrm{eV} \cdot{ }^{63}$ Based on the above data and the Badger's rule for the bond force constants, the interaction energy function for $\mathrm{K}$ ion with graphite surface was calculated with the Morse form for potential energy:

$$
E(r)=E_{a d}\left(1-e^{-a\left(r-r_{e q}\right)}\right)^{2}
$$

Where $\boldsymbol{a}=\sqrt{\frac{\boldsymbol{k}}{2 \boldsymbol{E}_{a d}}}, \boldsymbol{E}_{\boldsymbol{a d}}$ is the adsorption energy and $\boldsymbol{r}_{e q}$ is the equilibrium distance.

The bond force constant $\boldsymbol{k}$ is determined using the empirical Badger's rule, ${ }^{64}$ which has been extensively tested with quantum mechanical simulations. ${ }^{65}$ According to this rule, $\boldsymbol{k}=$ $\boldsymbol{A}\left(\boldsymbol{r}_{\boldsymbol{e q}}-\boldsymbol{B}\right)^{-3}$ with constant $\mathrm{A}=1.86 \mathrm{eV} \AA$, and constant $\mathrm{B}$ depends on the interacting atom row numbers in the periodic table. The value of $\mathrm{B}=0.85 \AA$ was used for the interaction of $\mathrm{K}$ ion with graphite. ${ }^{66}$

\section{Acknowledgment}

This work was supported by High-level Talents' Discipline Construction Fund of Shandong University (Grant No. 31370089963078), School Research Startup Expenses of Harbin Institute of Technology (Shenzhen) (Grant No. DD29100027), China Postdoctoral Science Foundation (Grant No. 2019M661276), Guangdong Basic and Applied Basic Research Foundation (Grant No. 2019A1515110756).

\section{References}

1. Z. P. Cano, D. Banham, S. Ye, A. Hintennach, J. Lu, M. Fowler and Z. Chen, Nature Energy, 2018, 3, 279289.

2. J. W. Choi and D. Aurbach, Nature Reviews Materials, 2016, 1, 16013.

3. G. Li, B. Huang, Z. Pan, X. Su, Z. Shao and L. An, Energy \& Environmental Science, 2019, 12, $2030-$ 2053.

4. W. Zhang, Y. Liu and Z. Guo, Science Advances, 2019, 5, eaav7412.

5. Y.-S. Xu, S.-Y. Duan, Y.-G. Sun, D.-S. Bin, X.-S. Tao, D. Zhang, Y. Liu, A.-M. Cao and L.-J. Wan, Journal of Materials Chemistry A, 2019, 7, 4334-4352.

6. X. Wu, Y. Chen, Z. Xing, C. W. K. Lam, S.-S. Pang, W. Zhang and Z. Ju, Advanced Energy Materials, 2019, 9, 1900343.

7. T. Hosaka, K. Kubota, A. S. Hameed and S. Komaba, Chemical Reviews, 2020, DOI: 10.1021/acs.chemrev.9b00463.

8. M. Okoshi, Y. Yamada, S. Komaba, A. Yamada and H. Nakai, Journal of The Electrochemical Society, 2016, 164, A54-A60.

9. J. Zhang, T. Liu, X. Cheng, M. Xia, R. Zheng, N. Peng, H. Yu, M. Shui and J. Shu, Nano Energy, 2019, 
60, 340-361.

10. C. Zhang, Y. Xu, M. Zhou, L. Liang, H. Dong, M. Wu, Y. Yang and Y. Lei, Advanced Functional Materials, 2017, 27, 1604307.

11. N. Xiao, W. D. McCulloch and Y. Wu, Journal of the American Chemical Society, 2017, 139, 9475-9478.

12. Z. Jian, W. Luo and X. Ji, Journal of the American Chemical Society, 2015, 137, 11566-11569.

13. L. Li, L. Liu, Z. Hu, Y. Lu, Q. Liu, S. Jin, Q. Zhang, S. Zhao and S. Chou, Angewandte Chemie International Edition, 2020, n/a.

14. L. Fan, R. Ma, Q. Zhang, X. Jia and B. Lu, Angewandte Chemie International Edition, 2019, 58, $10500-$ 10505 .

15. B. Cao, Q. Zhang, H. Liu, B. Xu, S. Zhang, T. Zhou, J. Mao, W. K. Pang, Z. Guo, A. Li, J. Zhou, X. Chen and H. Song, Advanced Energy Materials, 2018, 8, 1801149.

16. D. Li, M. Zhu, L. Chen, L. Chen, W. Zhai, Q. Ai, G. Hou, Q. Sun, Y. Liu, Z. Liang, S. Guo, J. Lou, P. Si, J. Feng, L. Zhang and L. Ci, Advanced Materials Interfaces, 2018, 5, 1800606.

17. W. Yang, J. Zhou, S. Wang, W. Zhang, Z. Wang, F. Lv, K. Wang, Q. Sun and S. Guo, Energy \& Environmental Science, 2019, 12, 1605-1612.

18. D. Li, X. Cheng, R. Xu, Y. Wu, X. Zhou, C. Ma and Y. Yu, Journal of Materials Chemistry A, 2019, 7, 19929-19938.

19. D. Li, X. Ren, Q. Ai, Q. Sun, L. Zhu, Y. Liu, Z. Liang, R. Peng, P. Si, J. Lou, J. Feng and L. Ci, Advanced Energy Materials, 2018, 8, 1802386.

20. Q. Sun, D. Li, J. Cheng, L. Dai, J. Guo, Z. Liang and L. Ci, Carbon, 2019, 155, 601-610.

21. Y. Xu, C. Zhang, M. Zhou, Q. Fu, C. Zhao, M. Wu and Y. Lei, Nature Communications, 2018, 9, 1720.

22. Z. Jian, S. Hwang, Z. Li, A. S. Hernandez, X. Wang, Z. Xing, D. Su and X. Ji, Advanced Functional Materials, 2017, 27, 1700324.

23. Y. Liu, Y.-X. Lu, Y.-S. Xu, Q.-S. Meng, J.-C. Gao, Y.-G. Sun, Y.-S. Hu, B.-B. Chang, C.-T. Liu and A.-M. Cao, Advanced Materials, 2020, 32, 2000505.

24. J. Zheng, Y. Yang, X. Fan, G. Ji, X. Ji, H. Wang, S. Hou, M. R. Zachariah and C. Wang, Energy \& Environmental Science, 2019, 12, 615-623.

25. Y. Wu, S. Hu, R. Xu, J. Wang, Z. Peng, Q. Zhang and Y. Yu, Nano Letters, 2019, 19, 1351-1358.

26. R. Zhang, J. Bao, Y. Wang and C.-F. Sun, Chemical Science, 2018, 9, 6193-6198.

27. K. Lei, C. Wang, L. Liu, Y. Luo, C. Mu, F. Li and J. Chen, Angewandte Chemie International Edition, 2018, 57, 4687-4691.

28. D. Li, Q. Sun, Y. Zhang, L. Chen, Z. Wang, Z. Liang, P. Si and L. Ci, ChemSusChem, 2019, 12, 2689-2700.

29. L. Fang, J. Xu, S. Sun, B. Lin, Q. Guo, D. Luo and H. Xia, Small, 2019, 15, 1804806.

30. D. Li, Y. Zhang, Q. Sun, S. Zhang, Z. Wang, Z. Liang, P. Si and L. Ci, Energy Storage Materials, 2019, 23, 367-374.

31. W. Zhang, W. K. Pang, V. Sencadas and Z. Guo, Joule, 2018, 2, 1534-1547.

32. W. Zhang, J. Mao, S. Li, Z. Chen and Z. Guo, Journal of the American Chemical Society, 2017, 139, 33163319.

33. Y. Zhao, J. Zhu, S. J. H. Ong, Q. Yao, X. Shi, K. Hou, Z. J. Xu and L. Guan, Advanced Energy Materials, 2018, 8, 1802565.

34. M. G. Boebinger, D. Yeh, M. Xu, B. C. Miles, B. Wang, M. Papakyriakou, J. A. Lewis, N. P. Kondekar, F. J. Q. Cortes, S. Hwang, X. Sang, D. Su, R. R. Unocic, S. Xia, T. Zhu and M. T. McDowell, Joule, 2018, 2, 1783-1799.

35. Y. Liu, Z. Sun, X. Sun, Y. Lin, K. Tan, J. Sun, L. Liang, L. Hou and C. Yuan, Angewandte Chemie 
International Edition, 2020, 59, 2473-2482.

36. L. Li, W. Zhang, X. Wang, S. Zhang, Y. Liu, M. Li, G. Zhu, Y. Zheng, Q. Zhang, T. Zhou, W. K. Pang, W. Luo, Z. Guo and J. Yang, ACS Nano, 2019, 13, 7939-7948.

37. G. Ma, X. Xu, Z. Feng, C. Hu, Y. Zhu, X. Yang, J. Yang and Y. Qian, Nano Research, 2020, 13, 802-809.

38. N. Zheng, G. Jiang, X. Chen, J. Mao, Y. Zhou and Y. Li, Journal of Materials Chemistry A, 2019, 7, 93059315.

39. J. Ge, L. Fan, J. Wang, Q. Zhang, Z. Liu, E. Zhang, Q. Liu, X. Yu and B. Lu, Advanced Energy Materials, 2018, 8, 1801477.

40. R. Zhang, J. Huang, W. Deng, J. Bao, Y. Pan, S. Huang and C.-F. Sun, Angewandte Chemie International Edition, 2019, 58, 16474-16479.

41. S. S. Fedotov, A. S. Samarin, V. A. Nikitina, D. A. Aksyonov, S. A. Sokolov, A. Zhugayevych, K. J. Stevenson, N. R. Khasanova, A. M. Abakumov and E. V. Antipov, Journal of Materials Chemistry A, 2018, 6, 14420-14430.

42. Y. An, H. Fei, G. Zeng, L. Ci, B. Xi, S. Xiong and J. Feng, Journal of Power Sources, 2018, 378, 66-72.

43. G. Ma, K. Huang, J.-S. Ma, Z. Ju, Z. Xing and Q.-c. Zhuang, Journal of Materials Chemistry A, 2017, 5, 7854-7861.

44. K. Share, A. P. Cohn, R. Carter, B. Rogers and C. L. Pint, ACS Nano, 2016, 10, 9738-9744.

45. M. Chen, W. Wang, X. Liang, S. Gong, J. Liu, Q. Wang, S. Guo and H. Yang, Advanced Energy Materials, 2018, 8, 1800171.

46. R. Zhao, H. Di, X. Hui, D. Zhao, R. Wang, C. Wang and L. Yin, Energy \& Environmental Science, 2020, 13, 246-257.

47. E. Olsson, J. Cottom, H. Au, Z. Guo, A. C. S. Jensen, H. Alptekin, A. J. Drew, M.-M. Titirici and Q. Cai, Advanced Functional Materials, 2020, 30, 1908209.

48. A. Sadezky, H. Muckenhuber, H. Grothe, R. Niessner and U. Pöschl, Carbon, 2005, 43, 1731-1742.

49. Z. Li, C. Bommier, Z. S. Chong, Z. Jian, T. W. Surta, X. Wang, Z. Xing, J. C. Neuefeind, W. F. Stickle, M. Dolgos, P. A. Greaney and X. Ji, Advanced Energy Materials, 2017, 7, 1602894.

50. S. L. H. Rebelo, A. Guedes, M. E. Szefczyk, A. M. Pereira, J. P. Araújo and C. Freire, Physical Chemistry Chemical Physics, 2016, 18, 12784-12796.

51. H. Shao, Y.-C. Wu, Z. Lin, P.-L. Taberna and P. Simon, Chemical Society Reviews, 2020, DOI: 10.1039/D0CS00059K.

52. Y. Chen, L. Qin, Y. Lei, X. Li, J. Dong, D. Zhai, B. Li and F. Kang, ACS Applied Materials \& Interfaces, 2019, 11, 45578-45585.

53. S. Zeng, X. Zhou, B. Wang, Y. Feng, R. Xu, H. Zhang, S. Peng and Y. Yu, Journal of Materials Chemistry $A, 2019,7,15774-15781$.

54. J. Ding, H. Zhang, H. Zhou, J. Feng, X. Zheng, C. Zhong, E. Paek, W. Hu and D. Mitlin, Advanced Materials, 2019, 31, 1900429.

55. Y. Cao, L. Xiao, M. L. Sushko, W. Wang, B. Schwenzer, J. Xiao, Z. Nie, L. V. Saraf, Z. Yang and J. Liu, Nano Letters, 2012, 12, 3783-3787.

56. V. Augustyn, J. Come, M. A. Lowe, J. W. Kim, P.-L. Taberna, S. H. Tolbert, H. D. Abruña, P. Simon and B. Dunn, Nature Materials, 2013, 12, 518-522.

57. T. Brezesinski, J. Wang, S. H. Tolbert and B. Dunn, Nature Materials, 2010, 9, 146-151.

58. H.-S. Kim, J. B. Cook, H. Lin, Jesse S. Ko, Sarah H. Tolbert, V. Ozolins and B. Dunn, Nature Materials, 2017, 16, 454-460.

59. W. Weppner, Journal of The Electrochemical Society, 1977, 124, 1569. 
60. Z. Shen, L. Cao, C. D. Rahn and C.-Y. Wang, Journal of The Electrochemical Society, 2013, 160, A1842A1846.

61. W. Wang, J. Zhou, Z. Wang, L. Zhao, P. Li, Y. Yang, C. Yang, H. Huang and S. Guo, Advanced Energy Materials, 2018, 8, 1701648.

62. G. Gómez-Santos, Physical Review B, 2009, 80, 245424.

63. F. Valencia, A. H. Romero, F. Ancilotto and P. L. Silvestrelli, The Journal of Physical Chemistry B, 2006, 110, 14832-14841.

64. R. M. Badger, The Journal of Chemical Physics, 1934, 2, 128-131.

65. J. Cioslowski, G. Liu and R. A. Mosquera Castro, Chemical Physics Letters, 2000, 331, 497-501.

66. D. R. Herschbach and V. W. Laurie, The Journal of Chemical Physics, 1961, 35, 458-464. 